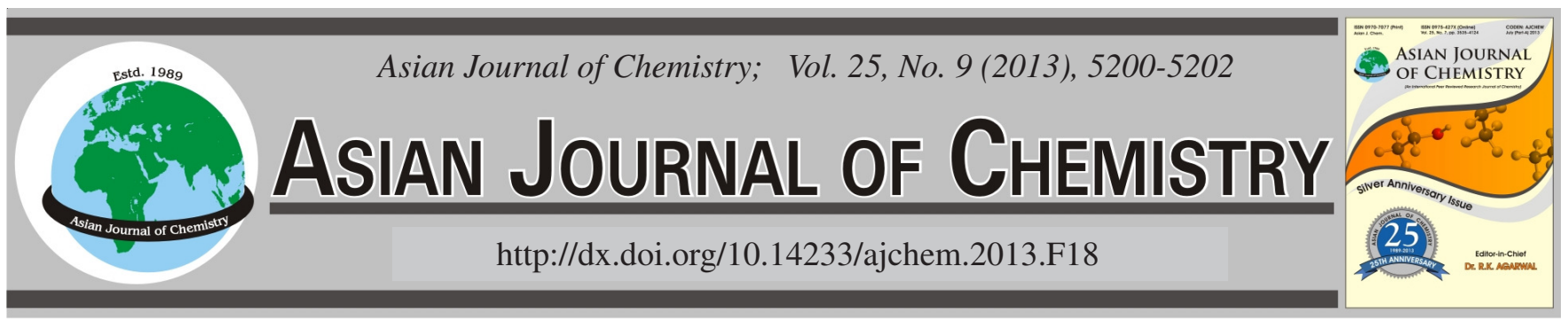

\title{
Study on the Dynamic Properties of Nitrile-Butadiene Rubber/Hindered Phenol Mixtures by Molecular Dynamics Simulation $\dagger$
}

\author{
Meng Song, Xiuying Zhao, Bo Qiao, Hua Zou and Sizhu Wu*
}

State Key Laboratory of Organic-Inorganic Composites, Beijing University of Chemical Technology, Beijing 100029, P.R. China

*Corresponding author: Fax: +86 10 64433964; Tel: +86 10 64444923; E-mail: wusz@ mail.buct.edu.cn

This paper reports the experimental and molecular simulation results of damping materials composed of nitrile-butadiene rubber (NBR) mixed with different hindered phenol (AO-80) mass ratios. The aim of this study was to determine how these AO-80 small molecules enhanced the damping behaviour of rubber mixtures from a microstructural point of view. Hydrogen bonds were formed between the AO- 80 small molecules and nitrile-butadiene rubber polymer chains. Compared to the other ratios, the NBR/AO-80 mixtures with a blending ratio of 100/68 had the highest number of hydrogen bonds, resulting in the maximum loss factor and highest modulus. Possible microscopic mechanisms responsible for the enhanced damping performance of the NBR/AO-80 materials were examined by a molecular simulation.

Key Words: Damping performance, Hydrogen bond, Molecular simulation, Dynamic properties.

ᄂ - - - - - - - - - - - - - - - - - - - - - - - - - - - - - -

\section{INTRODUCTION}

Rubber damping composites are vibration damping and noise reduction functional materials based on the viscoelastic behaviour. In the glass transition area, the internal friction produced by the motion of molecular chains can convert mechanical and sound energy to heat energy ${ }^{1}$. Nitrile-butadiene rubber (NBR) has a higher loss factor in rubber products and is commonly used in a range of applications. Hindered phenol AO-80 can effectively improve the damping properties of rubber mixtures due to hydrogen bonding between the AO-80 small molecules and nitrile-butadiene rubber polymer chains ${ }^{2}$. On the theoretical part, computer simulations are possibly the most valuable tool for analyzing the microstructure of materials with better control over the process than experiments, particularly under harsh conditions, such as extremely high or low temperatures, pressures and supercritical states ${ }^{3}$. A molecular dynamics (MD) simulation was designed to analyze the microstructure and examine the relationship between the damping properties and the hydrogen bonding of NBR/AO- 80 mixtures quantitatively.

\section{EXPERIMENTAL}

Nitrile-butadiene rubber (N220S, Japan Synthetic Rubber Co., Ltd., Tokyo, Japan) with an acrylonitrile mass fraction of $41 \%$ was used in all materials. AO-80 (ADK-
ATAB-AO-80) was supplied by Asahi Denka Co., Ltd. (Tokyo, Japan). All other chemicals and ingredients were purchased in China.

Sample preparation: The NBR/AO-80 mixtures with different blending mass ratios were mixed with compounding and crosslinking additives, including $5.0 \mathrm{phr} \mathrm{ZnO}, 2.0 \mathrm{phr}$ stearic acid, $0.5 \mathrm{phr}$ dibenzothiazole disulfide, $0.5 \mathrm{phr}$ diphenyl guanidine, $0.2 \mathrm{phr}$ tetramethylthiuram disulfide and $2.0 \mathrm{phr}$ sulfur. The mixtures were then kneaded on a two-roll mill at room temperature for $10 \mathrm{~min}$. The mixtures were then hot-pressed and crosslinked at $160{ }^{\circ} \mathrm{C}$ under a pressure of $15 \mathrm{MPa}$ for different periods of time and allowed to cool naturally to room temperature to obtain the NBR/AO-80 samples.

Mechanical analysis: A dynamic mechanical thermal analyzer (DMTA, VA3000 Rheometric Scientific Co. Ltd., USA) was used to obtain the dynamic viscoelasticity at frequencies ranging from $1 \mathrm{~Hz}$ to $1000 \mathrm{~Hz}$ and various temperatures from $-150{ }^{\circ} \mathrm{C}$ to $450{ }^{\circ} \mathrm{C}$. The heating rate was $3{ }^{\circ} \mathrm{C} /$ $\mathrm{min}$. The dimensions of the sample were $20 \mathrm{~mm}$ in length, 6 $\mathrm{mm}$ in width and approximately $1 \mathrm{~mm}$ in thickness. The tensile tests were carried out using a LRX Plus Tensile Tester (Lloyd instruments, USA) at a tensile rate of $500 \mathrm{~mm} / \mathrm{min}$.

Simulation strategies for NBR/AO-80 mixtures: The discover and amorphous cell modulus of the Materials Studio® suite software were used for the molecular dynamics simulation using the condensed-phase optimized molecular 
(1) $\mathrm{H}$<smiles>Cc1cc(CCC(=O)OCC(C)(C)C(O)O[O-])cc(C(C)(C)C)c1O</smiles>

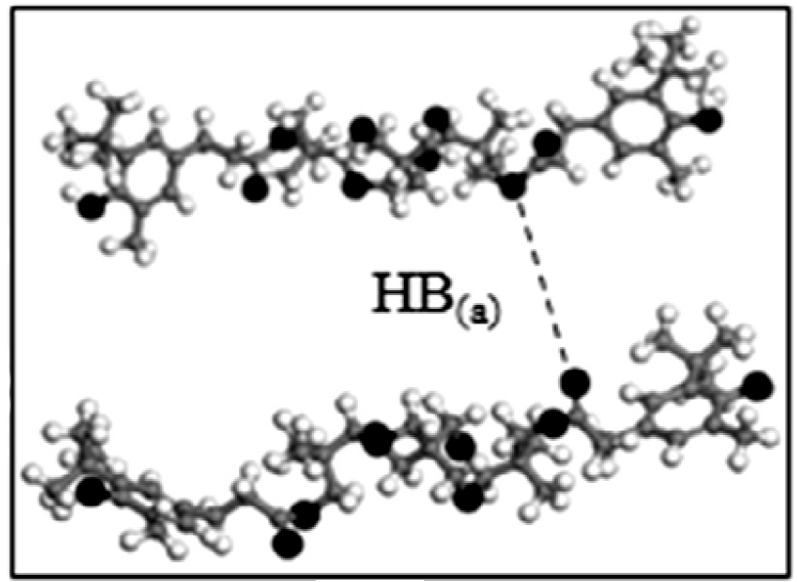

(c)

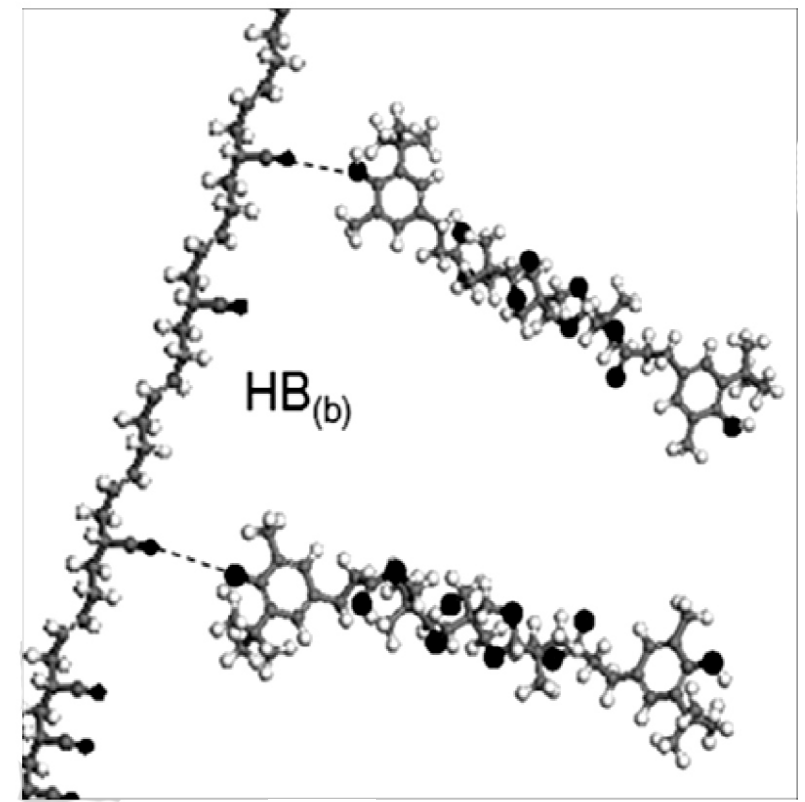

(d)

Fig. 1. Molecular structures of (a) AO-80, (b) nitrile-butadiene rubber and (c) HB(a) and (d) HB(b). (The white, small black, grey and big black spheres stand for $\mathrm{H}, \mathrm{N}, \mathrm{C}$ and $\mathrm{O}$ atoms, respectively; the black short line denotes $\mathrm{HB}$.)

potentials for Atomistic Simulation Studies (COMPASS) force field ${ }^{4}$. The molecular dynamics results revealed two types of hydrogen bonds (HBs) in the NBR/AO-80 mixtures. The first $\left[\mathrm{HB}_{(\mathrm{a})}\right]$ was between the phenolic hydroxyl groups -OH of AO80 (1,2 in Fig. 1(a)) and the carbonyl group - $\mathrm{CO}$ of $\mathrm{AO}-80$ [3,4 in Fig. 1(a)]. The second $\left[\mathrm{HB}_{(\mathrm{b})}\right]$ was between the phenolichydroxyl groups -OH of AO-80 (1,2 in Fig. 1(a)) and the nitrile groups $-\mathrm{CN}$ of nitrile-butadiene rubber ( 7 in Fig. 1(b)). Fig. 1(c) and Fig. 1(d) shows these two types of HBs, $\mathrm{HB}_{(\mathrm{a})}$ and $\mathrm{HB}_{(\mathrm{b})}$, respectively.

The corresponding mass ratios of NBR/AO- 80 were 100/ $13,100 / 27,100 / 41,100 / 55,100 / 68,100 / 82$ and 100/96, respectively, in which the simulation systems had similar ratios to the experimental samples.

\section{RESULTS AND DISCUSSION}

Analyze NBR/AO-80 mixtures microstructure by molecular dynamics simulation: The molecular dynamics method was used to obtain more detailed quantitative information on the hydrogen bonds in the mixtures. The nitrilebutadiene rubber polymer chains and some AO-80 small molecules were prepared in an amorphous cell to calculate the number and length, angle of the hydrogen bonds etc. The number of hydrogen bonds in the cell can be obtained by a molecular dynamics simulation. Fig. 2 shows the number of $\mathrm{HB}_{(\mathrm{a})}$ and $\mathrm{HB}_{(\mathrm{b})}$ in the NBR/AO-80 mixtures with different $\mathrm{AO}-$ 80 contents. The number of $\mathrm{HB}_{(\mathrm{a})}$ increased with increasing AO- 80 content because more small molecules of AO- 80 would increase the chance of forming this kind of hydrogen bond. Compared to these two types of hydrogen bonds in the NBR/ AO-80 mixtures, there were more $\mathrm{HBs}_{(\mathrm{b})}$ than $\mathrm{HBs}_{(\mathrm{a})}$, suggesting that $\mathrm{HB}_{(\mathrm{b})}$ was formed more easily in the mixtures and played a more important role than $\mathrm{HB}_{(\mathrm{a})}$. As the $\mathrm{AO}-80$ content was increased, the number of hydrogen bonds increased first and then decreased. This suggests that at a weight ratio of 100/ 68(NBR/AO-80), most of the hydrogen bonds can be found, indicating the strongest interaction between nitrile-butadiene rubber and AO-80 in NBR/AO-80 (100/68) mixtures. A larger number of AO- 80 molecules would induce a steric effect that would decrease the chance to form hydrogen bonds ${ }^{5,6}$.

Dynamic mechanical properties: In the transitional region between the glassy and rubbery states (near the glass transition temperature), the viscoelastic behaviour of polymeric materials can efficiently determine the damping performance ${ }^{7}$. In this region, the macromolecular chain segments, but not entire macromolecules, tended to vibrate in phase with an external vibration. On the other hand, the changes in conformation normally cannot keep pace with the imposed vibration, 


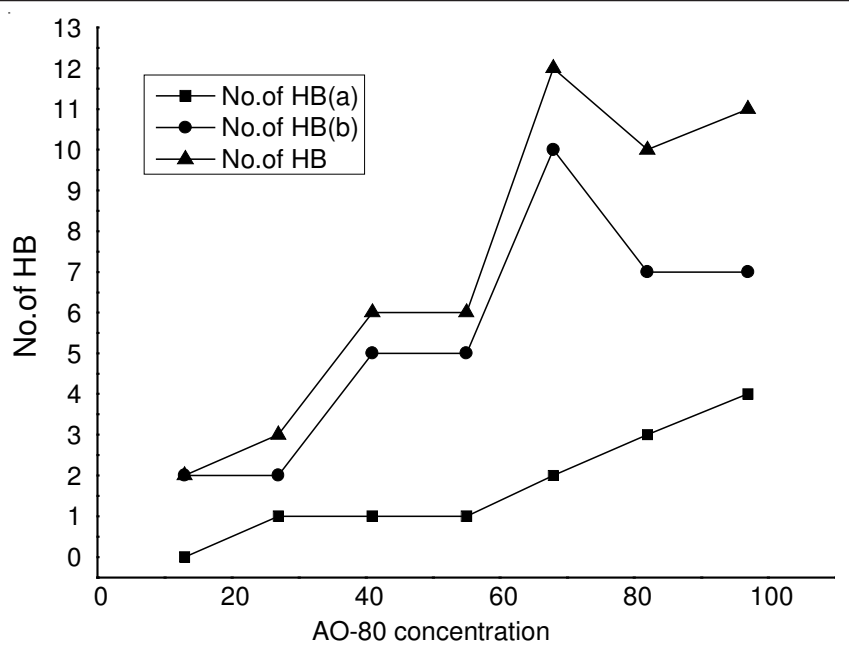

Fig. 2. The number of $\mathrm{HB}, \mathrm{HB}(\mathrm{a}), \mathrm{HB}(\mathrm{b}) v s$. AO- 80 concentration in the NBR/AO-80 mixture systems

resulting in internal friction and energy dissipation ${ }^{8}$. Of the DMTA results, the loss factor tand reflects the internal and external friction and expresses the ratio of dispersed energy in one deformation cycle to the energy accumulated during the deformation process. The damping performance of the material improved with increasing $\tan \delta$.

Fig. 3 shows that there was only one $\tan \delta$ peak for each NBR/AO-80 mixture. Compared to the maximum tand of each curve, the NBR/AO-80 mixture with a ratio of 100/60 was significantly higher than the others. This is because most $\mathrm{HBs}(\mathrm{b})$ formed between nitrile-butadiene rubber and $\mathrm{AO}-80$ molecules at that point, which provide improved compatibility.

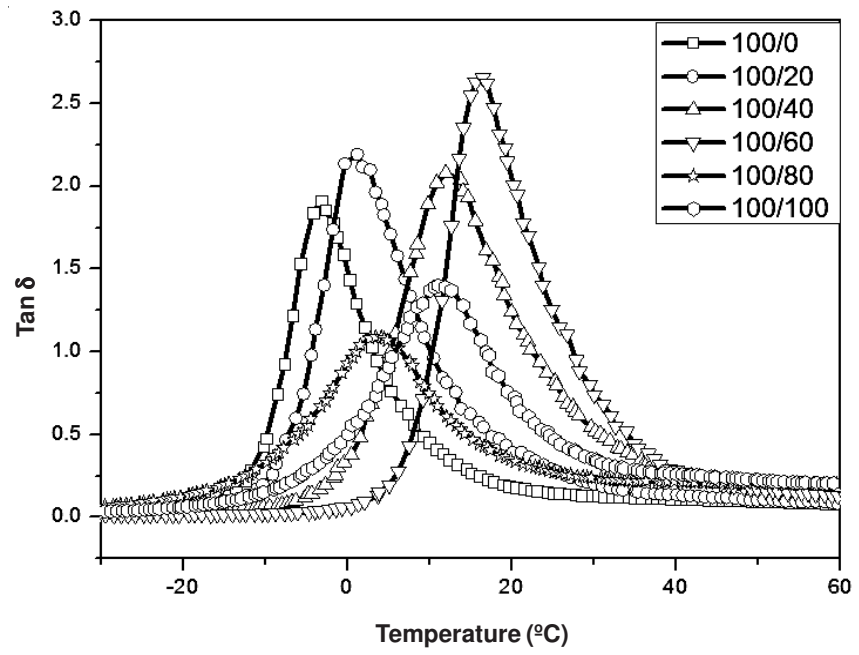

Fig. 3. Temperature dependence of the loss factor $(\tan \delta)$ values for nitrilebutadiene rubber and NBR/AO-80c mixtures

Static mechanical properties: Fig. 4 shows the detailed tensile modulus of the NBR/AO-80 mixtures as a function of the AO- 80 mass ratios. At an AO- 80 concentration of 60 , the tensile modulus was superior to the others due to the strong interactions between the nitrile-butadiene rubber and AO-80 molecules. This corresponds to the highest tensile modulus of NBR/AO-80.

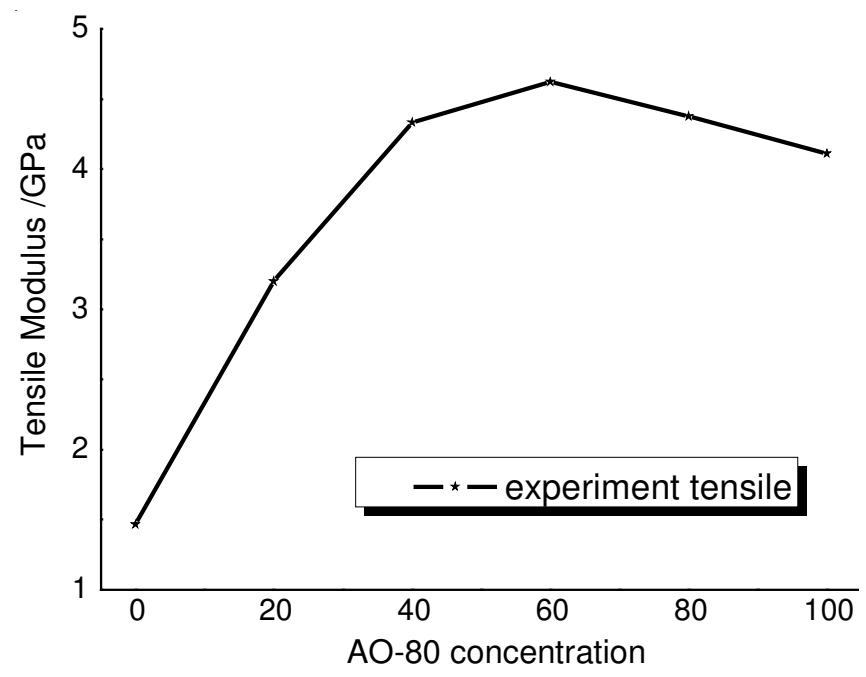

Fig. 4. Tensile modules vs. AO- 80 concentration by tensile tests

\section{Conclusion}

This study examined the damping mechanism of NBR/ AO-80 mixtures by molecular dynamics simulations and experimental tests including DMTA and tensile tests. According to the molecular dynamics results, the NBR/AO- 80 mixtures had a better damping performance when there was maximum number of HBs, such as in the NBR/AO-80(100/68) system. The damping performance enhancement provided by hydrogen bonding was due to the increasingly strong interactions between nitrile-butadiene rubber and AO-80. This was confirmed by the DMTA and tensile tests. Compared to the other ratios, the NBR/AO-80(100/60) showed better damping properties and the highest tensile modulus. This suggests that a molecular dynamics simulation plays a more significant role in damping materials research. This study highlights the importance of a suitable proportion of rubber blended with small hindered phenol molecules in the design of damping materials.

\section{ACKNOWLEDGEMENTS}

This project was supported by the National Science Foundation of China (50973007) and the Natural Science Foundation for the Youth (51103006)

\section{REFERENCES}

1. A.A. Gusev and K. Feldman, Macromolecules, 43, 2638 (2010).

2. X.Y. Zhao, P. Xiang, M. Tian, H. Fong, R. Jin and L.Q. Zhang, Polymer, 48, 6056 (2007).

3. G. Marque, J. Verdu, V. Prunier and D. Brown, J. Polym. Sci. B: Polym. Phys., 48, 2312 (2010).

4. H. Sun, J. Phys. Chem. B, 102, 7338 (1998).

5. A. K-V. Hossein, C. Paola and M.P. Florian, Macromolecules, 41, 7211 (2008).

6. L. Alenka and C. David, Nature, 379, 791 (1996).

7. K. Urayama, T. Kawamura and S. Kohjiya, Polymer, 50, 347 (2009).

8. X.F. Ma, W.H. Zhu, J.J. Xiao and H.M. Xiao, J. Hazard. Mater, 156, 201 (2008) 